\title{
Etching Characteristics and Profile Control in a Time Multiplexed Inductively Coupled Plasma Etcher
}

\author{
A. A. Ayón, C. C. Lin, R. A. Braff, and M. A. Schmidt \\ Department of Electrical Engineering and Computer Science (EECS)
}

\begin{abstract}
R. Bayt
Department of Aeronautics and Astronautics

Microsystems Technology Laboratories

Massachusetts Institute of Technology
\end{abstract}

H. H. Sawin

Department of Chemical Engineering \& EECS

\begin{abstract}
This paper reports on a complete designed experiment of a deep reactive ion etch process in which matrices of 8 and 4 variables were explored in order to optimize uniformity, anisotropy, Aspect Ratio Dependent Etching (ARDE), photoresist and silicon etching rate. A database results from these experiments which permits customization of operating conditions to obtain desired etch characteristics.
\end{abstract}

\section{INTRODUCTION}

Until the advent of high density plasma etchers, the options for fabricating High Aspect Ratio Structures (HARS) in silicon, such as reactive ion etching (RIE) and electron cyclotron resonance (ECR), had limited success in fulfilling the requirements of high etch rate, good selectivity to masking material, anisotropy and compatibility with other processes. A recent altemative that is satisfying the need of such processes is the time multiplexed deep etcher (TMDE) patented by Robert Bosch Gmbh [1]. This approach utilizes an etching cycle flowing only $\mathrm{SF}_{6}$ (figure 1), and then switches to a sidewall passivating cycle using only $\mathrm{C}_{4} \mathrm{~F}_{8}$.

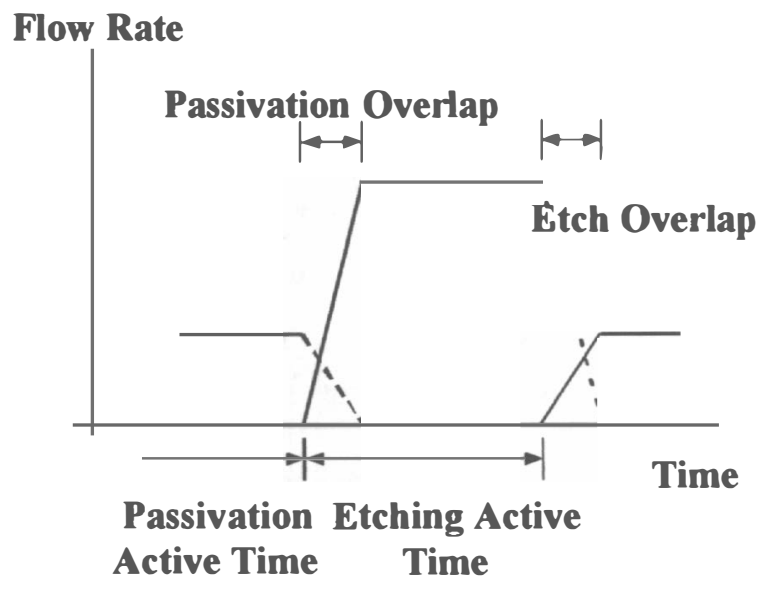

Figure 1. Graph showing the gas flow cycles during plasma etching. Note the overlaps caused by the finite time response of the flow controllers.
During the subsequent etching cycle, the passivating film is preferentially removed from the bottom of the renches due to ion bombardment, while preventing etch of the sidewalls. The final result is anisotropic sidewalls that exhibit scalloping (figure 2), with peak to valley amplitudes as low as $50 \mathrm{~nm}$. Higher electrode power to pressure ratios and shorter etching cycles reduce this effect.
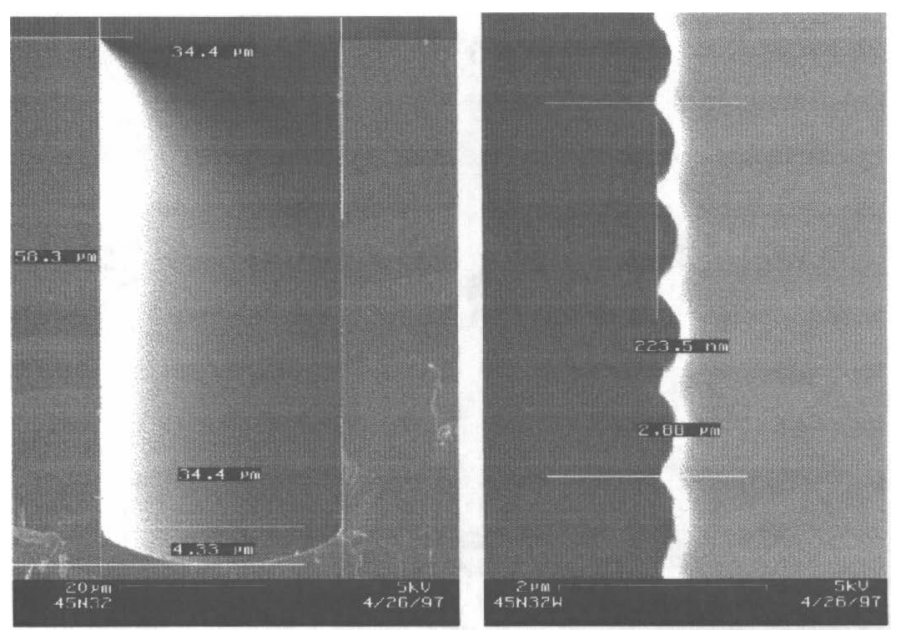

Figure 2. Micrograph view of an anisotropic etch (left) and the scalloping observed on the walls due to the periodic etch/deposition.

The success of Bosch's TMDE scheme, hinges upon the deposition of the inhibiting films. These films prevent the etching of the sidewalls by $\mathrm{SF}_{6}$ discharges that contain large concentrations of atomic fluorine that spontaneously etches silicon. $\mathrm{SF}_{6}$ discharges lack polymer forming species to block spontaneous etching [2].

By supressing the time multiplexing, the equipment can be run with continuous flows of $\mathrm{SF}_{6}$ or $\mathrm{C}_{4} \mathrm{~F}_{8}$. With $\mathrm{SF}_{6}$ it is possible to achieve isotropic etch rates as high as $1380 \mathrm{~A} / \mathrm{sec}$. Using $\mathrm{C}_{4} \mathrm{~F}_{8}$, teflon-like films can be deposited for use as anti-stiction films.

\section{EXPERIMENTAL DETAILS}

This work was performed using a Surface Technology Systems Multiplex ICP. The equipment includes two independent 13.56 $\mathrm{MHz}$ RF power sources: a $1000 \mathrm{~W}$ supply for a single-turn inductive coupling coil around the etching chamber to create the plasma, and a $300 \mathrm{~W}$ supply connected to the wafer electrode to vary the RF bias 


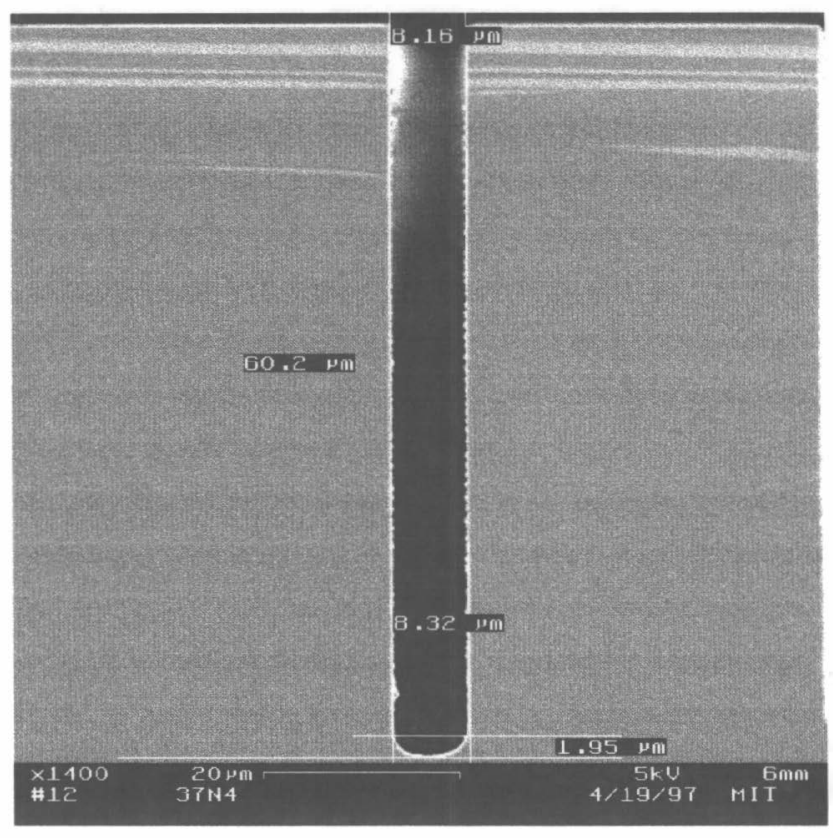

(a)

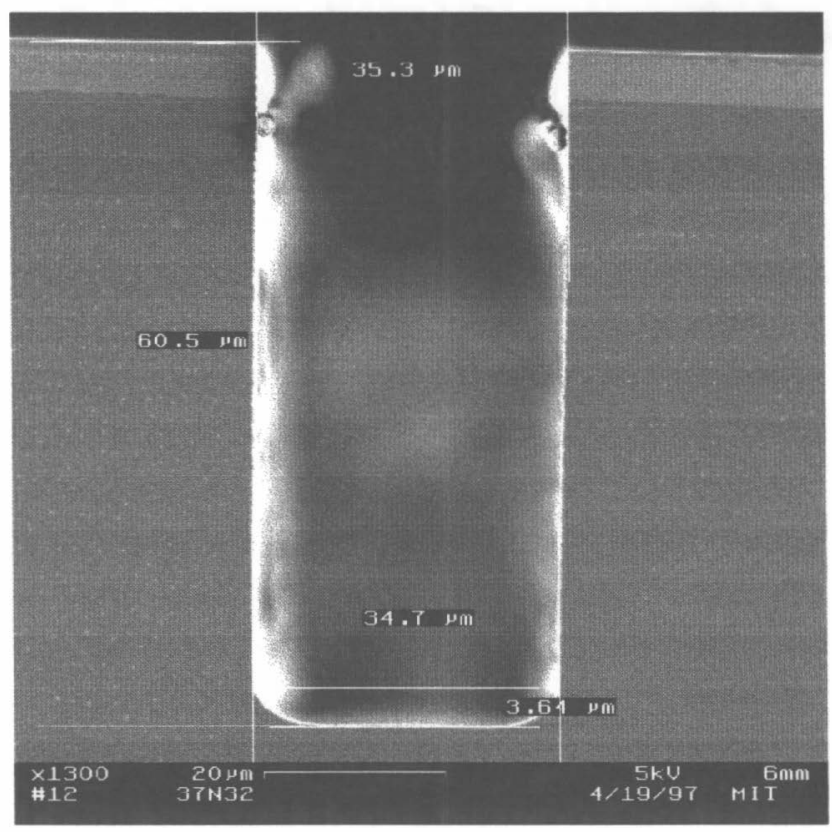

(b)

Figure 5. Trenches of width $8.32 \mu \mathrm{m}$ in (a) and $35.3 \mu \mathrm{m}$ in (b). Their measured depth differs by only $0.3 \mu \mathrm{m}$.

Uniformity values were obtained by comparing the depth of trenches of nominal width of $64 \mu \mathrm{m}$ in the middle of the wafer, with trenches located $3 \mathrm{~cm}$ away. This variable is important because of its influence in determining the overetch time needed to completely clear features throughout the wafer. In the low electrode power region $(\sim 8 \mathrm{~W})$, this variable benefits from lower $\mathrm{SF}_{6}$ flow rate, while in the mid to high applied electrode power regions $(\sim 12 \mathrm{~W})$, it is necessary to increase the $\mathrm{SF}_{6}$ llow rate. In general, lower operating pressure settings are benefitial for this response because the diffusivity varies inversely with the pressure.

Anisotropy is of importance in every application, and the ability to tailor the slope of trench walls is one characteristic of this deep silicon etching tool. As expected, anisotropy has a well defined dependence on applied electrode power and chamber pressure [9]. Anisotropy increases as the applied RF-bias electrode power is increased.

With pressure the behavior of this response is different. Initially, anisotropy increases with pressure increases, as thicker polymer films are deposited protecting the sidewalls. However, as the pressure is increased even further, the reduction in the average ion energy as well as the increase in the ion angle of incidence combine to produce deleterious effects on anisotropy.

It was also observed the relevance of $\mathrm{SF}_{6}$ flow rate in tailoring the anisotropy. In general, higher $\mathrm{SF}_{6}$ flow rates decrease the anisotropy and promote surface roughening (figure 6).
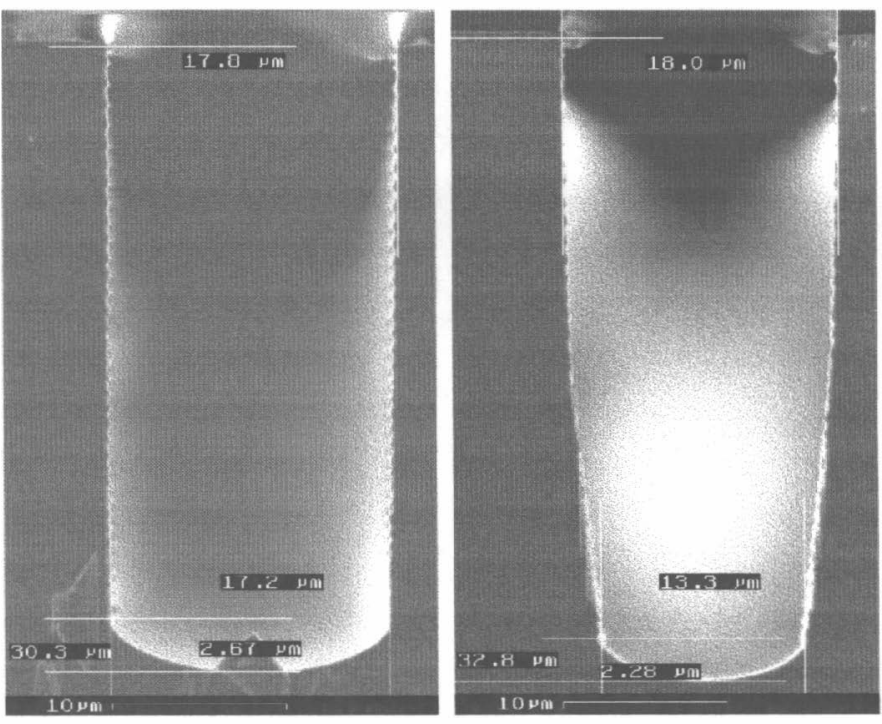

Figure 6. Micrographs of trenches etched in 10 minutes with an $\mathrm{SF}_{6}$ flow rate of $85 \mathrm{sccm}$ (left) and $125 \mathrm{sccm}$ (right) respectively.

Among the applications of the obtained information is the etching of deep narrow trenches like the one shown in figure 7 . In that figure, the trench presented has an average width of $12 \mu \mathrm{m}$ and a measured depth of $404 \mu \mathrm{m}$. Narrower trenches and submicron thin walls are also possible and this is shown in figure 8 .

Other applications include the utilization of the passivation films to control the notching effect when etching SOI wafers. This is accomplished by depositing a thicker polymer film when approaching the buried dielectric layer (figures 9).

\section{CONCLUSIONS}

The observed behavior presented in this report is an important tool to locate and optimize operating conditions to etch high aspect ratio structures. The performance of this deep reactive ion etcher allows the tailoring of etch rates of $4+\mu \mathrm{m} / \mathrm{min}$ with anisotropic profiles, nonuniformities of less than $4 \%$ across the wafer, and ARDE control with a depth variation of less than $1 \mu \mathrm{m}$ for trenches of dissimilar width. 
potential of the wafer with respect to the plasma. This arrangement permits the independent control of the energy of the ions reaching the substrate as well as the ion flux [3].

Backside helium pressurization is used to provide good heat transfer between the wafer and the electrode to maintain a constant wafer temperature. Low temperatures reduce the etching rate of the photoresist, thereby allowing its use as a mask for etching silicon. The photoresist can also be used as a bonding material for mounting the device wafer to a handle wafer during processes requiring etching through a wafer [4]. This mounting is required to prevent helium leaks into the chamber. Device wafers can also be mounted on quartz wafers for visual verification of the etch completion.

It is possible to operate with a predetermined common pressure for both etching and passivating active cycles, or with a fixed angular position for the opening of the automatic pressure control valve (APC). In the first case the position of the throttle valve (or APC valve) varies as the gas flow changes during each cycle. In the latter case, the position of the throttle valve is fixed and the pressure is determined by the gas flow rate. The results presented in this report used this latter approach. Higher values of the APC valve position in degrees correspond to higher pressures. However, the trip pressure is fixed at $90 \mathrm{mT}$ creating an upper pressure limit in these experiments.

For the eight-variable experiment the samples were prepared in the following fashion: 4" single crystal silicon $<100>$ wafers were coated with photoresist AZ4620 (Hoechst Celanese, Sunnyvale, CA) spun at $3000 \mathrm{rpm}$ (thickness $\approx 6 \mu \mathrm{m}$ ) and baked in a convection oven at $90^{\circ} \mathrm{C}$ for 30 minutes. The samples were then exposed in a contact aligner with a wavelength of $320 \mathrm{~nm}$ and power density of 6 $\mathrm{mW} / \mathrm{cm}^{2}$, developed with AZ440 (Hoechst Celanese, Sunnyvale, CA), and baked again at $90^{\circ} \mathrm{C}$ for 30 minutes. We used an SEM to study each etched sample. The etching time for these samples was fixed at 30 minutes each.

In order to obtain information on the influence of coil power during etching, an additional four-variable experiment was also performed. This matrix consisted of samples prepared in the following fashion: 4" single crystal silicon <100> wafers were coated with photoresist OCG 825 (Shipley, Marlboro, MA), with viscosity $20 \mathrm{cs}$, baked and exposed in the same fashion but developed with OCG 934 (1:1). In this case the expected photomasking material thicknes is approximately $1 \mu \mathrm{m}$. We used an optical interferometer to measure the thickness of the photoresist layer before and immediately after etching each sample, and a profilometer to measure the depth of the etched trenches. All etches had a duration of 3 minutes.

These sets of experiments are adequate to fit a quadratic model and were analyzed using commercial software. The systematic investigation produced response surfaces [5] that enable us to predict appropriate operating conditions for different processing requirements.

\section{MEASURED PERFORMANCE}

The etching rate of silicon has a predominant dependence on applied coil power (figure 3 ), because this input determines the degree of ionization and dissociation of the glow discharge. Although not seen in figure 3, this response also benefits from higher $\mathrm{SF}_{6}$ flow rates as well as higher applied electrode power settings. Increasing electrode power during the etching cycle increases primarily the ion bombardment energy and secondarily the ionization and dissociation of the discharge, all of which increase the etching rate. For low $\mathrm{SF}_{6}$ flows, power increases only have a marginal effect on etching rate. At low flows the concentrations of products $\left(\mathrm{SiF}_{4}\right)$ that dissociate and redeposit increases [6].

The etching rate dependence on trench width, also known as ARDE [7, 8], varies with operating conditions (figure 4) and, therefore, it is also feasible to control this effect. ARDE benefits with high $\mathrm{SF}_{6}$ flow rates because of the reduction of product species in the discharge that contribute to redeposition. An example that exhibits small ARDE is shown in figure 5. This was accomplished by using an $\mathrm{SF}_{6}$ flow rate of $140 \mathrm{sccm}$.

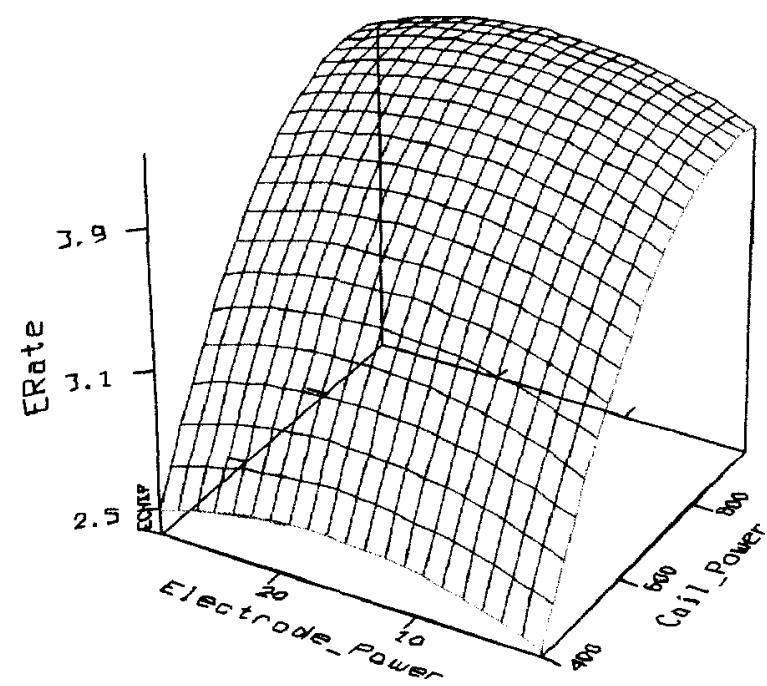

Figure 3. Silicon etching rate $(\mu \mathrm{m} / \mathrm{min})$ dependence on applied RFbias electrode power (W) and RF-inductive coil power (W).

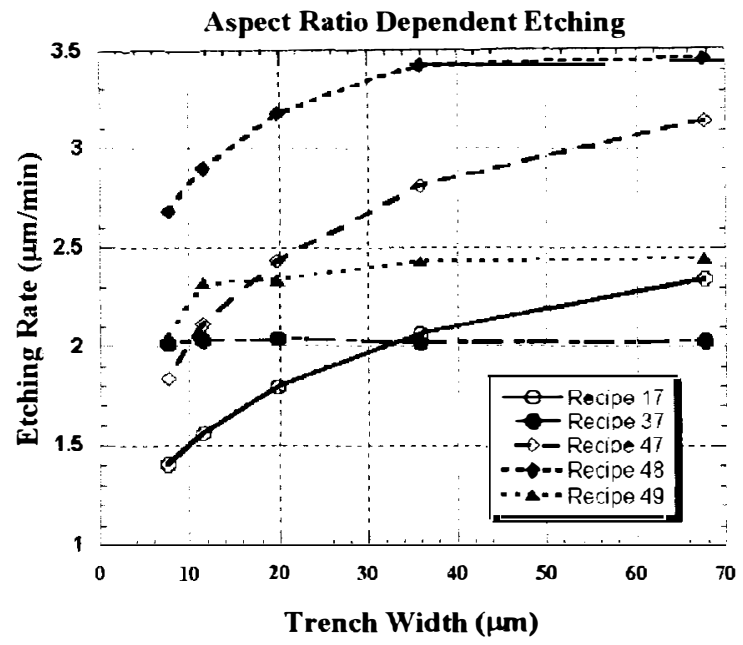

Figure 4. Aspect Ratio dependent Etching variation with trench width for different operating conditions.

Low photoresist etching rate is necessary for robust operation This response is strongly influenced by the applied electrode power, because this variable determines the ion bombardment energy. Lower electrode power settings are always favorable for achieving high selectivities. Furthermore, higher pressure settings also benefit this response. 


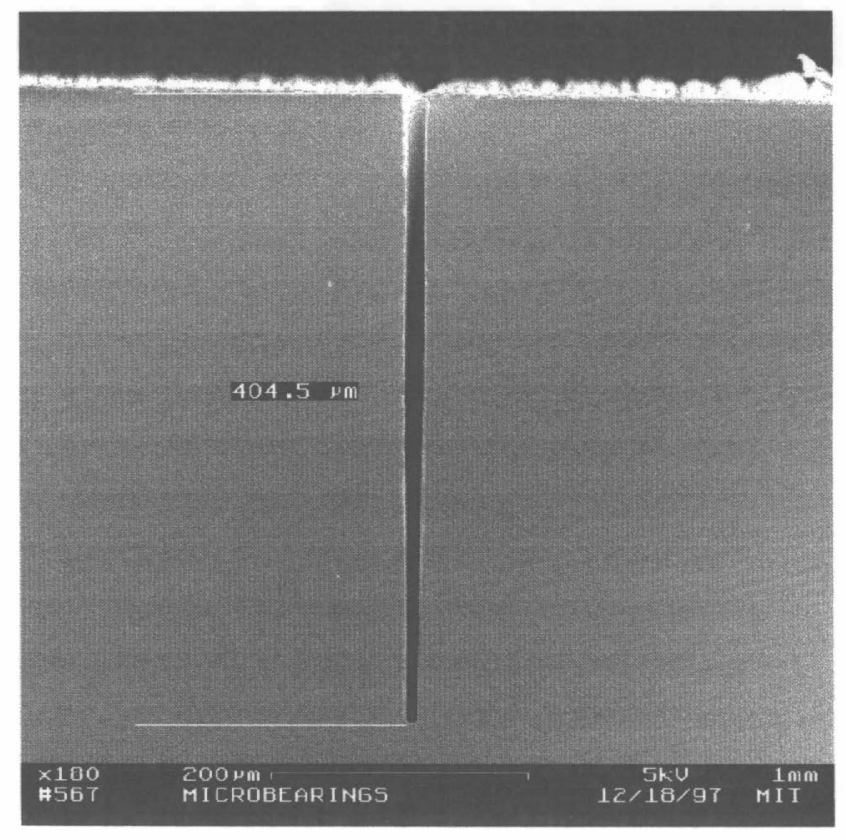

Figure 7. Micrograph of a rench etched applying $600 \mathrm{~W}$ during the passivation cycle and $750 \mathrm{~W}$ during the etching cycle.
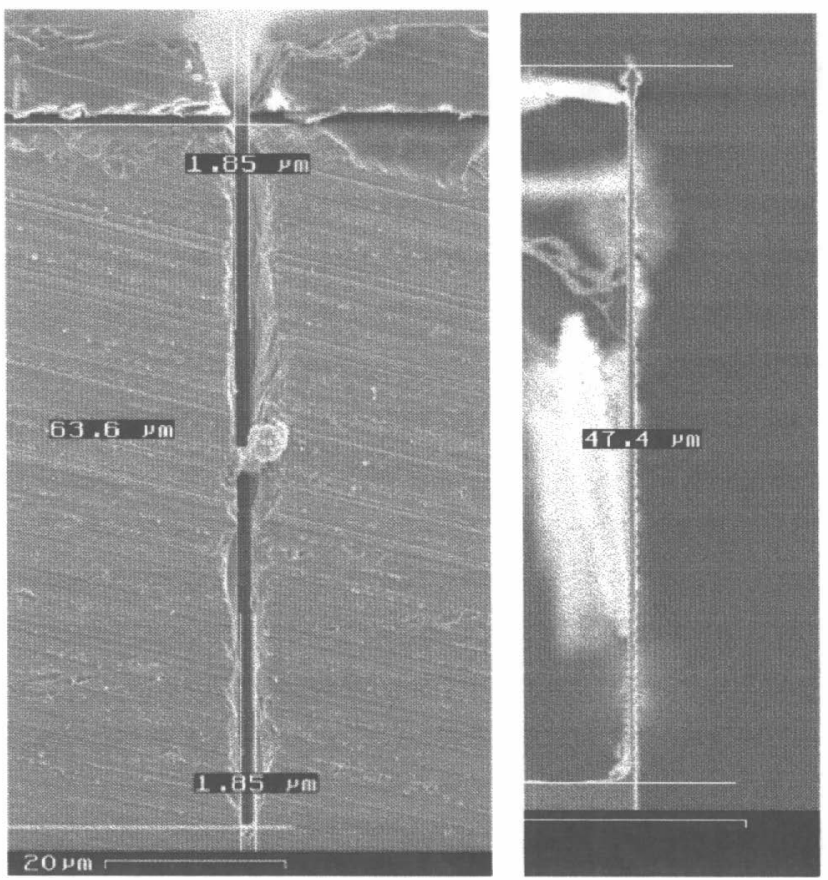

Figure 8. Micrograph of a trench $1.85 \mu \mathrm{m}$ wide and $63.6 \mu \mathrm{m}$ deep on the left, and a wall $0.8 \mu \mathrm{m}$ thick and $47.4 \mu \mathrm{m}$ tall on the right.
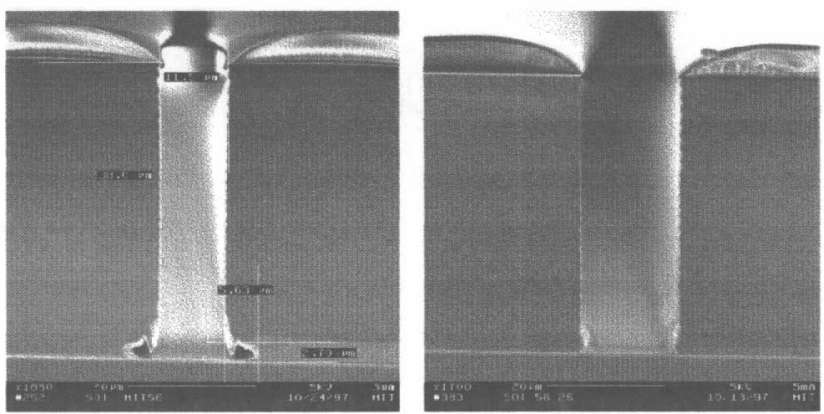

Figure 9. The footing effect appears when the etch stops on a buried oxide layer. It is clearly seen in the left micrograph. This effect can be suppressed controlling the passivation films as shown in the right micrograph.

\section{ACKNOWLEDGMENTS}

We thank Dr. R. Paur, U.S. Anny Research Office, and Dr. R. Nowak, DARPA, for support of this project, and a NSF Fellowship (R.A.B). The cooperation of the staff of the Microsystems Technology Laboratories at MIT is also appreciated.

\section{REFERENCES.}

1. Robert Bosch Gmbh, patents 4855017 and 4784720 (USA), and 4241045Cl (Germany).

2. A. J. Roosmalen, J. A. G. Baggerman and S. J. H. Brader, "Dry Etching for VLSI", p. 113, Plenum Press (1991).

3. M. A. Lieberman and A. J. Lichtenberg, "Principles of Plasma Discharges and Materials Processing”, p. 387, John Wiley, 1994. 4. R. Bayt, A. A. Ayón and K. Breuer, "A Performance Evaluation of MEMS-based Micronozzles", $33^{\text {rd }}$ AIAA/ASME/SAE/ASEE

Joint Propulsion Conference \& Exhibit, Seattle (1997).

5. I. Tepermeister, N. Blayo, F. P. Klemens, D. E. Ibbotson, R. A.

Gottscho, J. T. C. Lee and H. H. Sawin, "Comparison of Advanced Plasma Sources for Etching Applications. I. Etching rate, Unifomity, and Profile Control in a Helicon and a Multiple Electron Cyclotron Resonance Source”, J. Vac. Sci. Technol., B12, 2310 (1994).

6. D. C. Gray, I. Tepenneister and H. H. Sawin, "Phenomenological Modeling of ion-enhanced surface kinetics in fluorine-based plasma etching", J. Vac. Sci. Technol., B11, 1243 (1993).

7. R. A. Gottscho, C. W. Jurgensen and D. J. Vitkavage,

"Microscopic uniformity in plasma etching", J. Vac. Sci. Technol. B10, 2133 (1992).

8. J. Logan, K. Petersen, E. H. Klaassen, M. Noworolski, N. Maluf and W. McCulley, Proceedings of the third International Symposium on Semiconductor Wafer Bonding: Physics and Applications, Vol. 95-7, pp. 489-496, 1995.

9. C. B. Zarowin, "Relation between the RF discharge parameters and plasma etch rates, selctivity and anisotropy”, J. Vac. Sci. Technol., 2A, 1537 (1984). 